\title{
Acrylamide-A Harmful Chemical Present in Food Entities
}

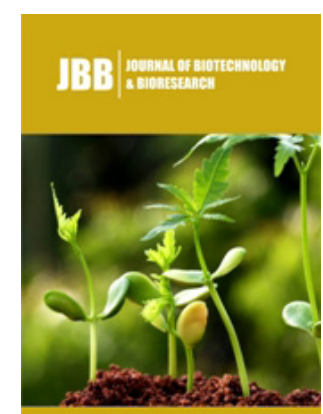

*Corresponding author: Naseem Zahra, Food and Biotechnology Research Centre, PCSIR Laboratories Complex, Pakistan

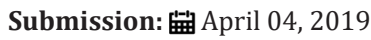

Published: 眥June 21, 2019

Volume 2 - Issue 1

How to cite this article: Naseem $Z^{*}$ Bukhtawar T, Rabea Y, Imran K, M Khalid $S$ et al. Acrylamide-A Harmful Chemical Present in Food Entities. J Biotech Biores.2(1). JBB.000527.2019.

Copyright@ Naseem Zahra. Senejani, This article is distributed under the terms of the Creative Commons Attribution 4.0 International License, which permits unrestricted use and redistribution provided that the original author and source are credited.

\author{
Naseem Zahra*, Bukhtawar Tariq, Rabea Yaseen, Imran Kalim, M Khalid \\ Saeed, Muhammad Ahsan Ashraf and Hamza Amin \\ Food and Biotechnology Research Centre, Pakistan
}

\begin{abstract}
Acrylamide presence in food has become a serious issue as it leads to cancer formation. Acrylamide is present in many of daily use products and is potentially hazardous for public health as well as environment. Acrylamide a simple organic compound that is responsible for causing cancer, neuro-degenerative diseases as well as other reproductive issues. Acrylamide is present in most of our food products and get worse with the cooking or heating process. It accounts for major health concerns because of its high-level consumption especially by young generation, which is fond of processed and baked food now-a-days. The conversion of acrylamide into carcinogenic agent is by the reaction called as Maillard reaction, which often leads to the browning or change in the food. time exposure to a substance containing acrylamide can be source of cancer or other disorders. The main purpose of this review is to summarize the methods for the detection of acrylamide, its major health concerns, its mitigation as well as its permissible limits along with its formation.
\end{abstract}

Keywords: Acrylamide; Harmful; Carcinogen; Food

\section{Introduction}

The Swedish national Food Administration reported the presence of acrylamide in 2002 [1]. Maillard reaction is the reaction which causes the redness or browning of food during baking, frying or roasting of food items most commonly potato chips, fried potatoes, brown bread or cornflakes and in this reaction acrylamide is produced as a side product by the reaction of reducing sugars like glucose and fructose with amino acid asparagine [2,3]. Cooking is the major factor that influences the production of acrylamide. The amount and levels of acrylamide production thus depends on cooking time, temperature along with the humidity or moisture and most importantly, the amount of reducing sugars and asparagine in uncooked food decides that to what extent there will be the presence of acrylamide in a specific food entity.

\section{What is Acrylamide?}

Acrylamide (or acrylic amide) is a simple chemical compound with low molecular weight of $71.09 \mathrm{~g}$ and is an odorless crystalline solid with high property of solubility in water, organic solvents. Its chemical formula is $\mathrm{C}_{3} \mathrm{H}_{5} \mathrm{NO}$ and suggested name by IUPAC name 2-propenamide [4]. Acids, bases, oxidizing agents, iron and salts are not compatible with 2-propenamide because of its severe reactivity. Decomposition of acrylamide results in the formation of carbon dioxide, carbon monoxide and oxides of nitrogen. Most commonly, acrylamide is the major ingredient of polyacrylamide used in gel electrophoresis in molecular biology laboratories. In industries, acrylamide copolymers are mostly in use for paper, dyes and plastic formation along with the cleaning of drinking water and sewage treatment. It also plays a major part in cosmetic formation and food packaging. Very minute amount of acrylamide endures for long time in the products. Trace amounts of acrylamide generally remain in these products [5]. Baking or heating of food especially starchy foods such as fries, potatoes, crackers or certain

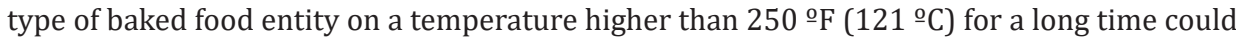
trigger the production of carcinogenic chemicals such as acrylamide. French fries are the one with the highest levels of acrylamide besides all of the food items [4]. Acrylamide is a simple organic compound, but it has both acidic and basic characteristics and just minute amount is enough for causing nervous spasm, cancer in animals and humans. It exhibits a different property in a way that it finds a way on its own to a food product and do not need the assistance of any other chemical to make it more toxic [6]. 
Because of presence of high amount of starch in potato, the food product with acrylamide as when subjected to high temperatures acrylamide become a serious health hazard [7]. Potato chips and fries testing enabled researchers to record high levels of acrylamide up to 3000 and even maximum $4000 \mu \mathrm{g} / \mathrm{kg}$. The detection of high levels confirmed its toxicity as a carcinogenic and neurodegenerative [8-12]. Decrease in the consumption of natural foods, change in lifestyles and increased preferences of processed and baked food items have made acrylamide a serious health hazard from the past few years [13]. Younger generation is common victim of acrylamide because of their sedentary lifestyles; they prefer snacks and more fast food intake and are thought at more at risk due to maximum amount of acrylamide consumption [14,15]. According to a survey among baked and snack foods, potato chips is most commonly liked and consumed by teens and young generation and is consumed in large amount [16]. The total acrylamide contribution by French fries and potato chips is $56 \%$ in the western dietary intake of young generation [17]. Keeping in view the too much likeness of young generation, researchers focused on how acrylamide is formed and how is controlled by few strategies [18]. Acrylamide formation is on the reactivity of reducing sugars or carbonyls and other model systems along with different applied conditions [19]. The participation of asparagine in Maillard reaction is regarded the basic precursor that leads to the formation of acrylamide. It was to find that the heat-treated food products containing high amount of asparagine results in the formation of high levels of acrylamide means they have a direct relation [20]. The increased levels of acrylamide in potatoes is also dependent upon the fertilizer used [21] along with storing temperature [22]. As in case of potatoes if we compared the effect of storing temperature in the formation of acrylamide the potatoes stored at $2{ }^{\circ} \mathrm{C}$ have high sugar content as compared to potatoes stored at $20{ }^{\circ} \mathrm{C}$ and are more likely to have more acrylamide levels when subjected to high cooking temperature for prolong time. For instance, the storage of potatoes at $2{ }^{\circ} \mathrm{C}$ results in increased free sugar content that converts to higher acrylamide levels during cooking as compared with potatoes stored at $20{ }^{\circ} \mathrm{C}$ (Figure 1); [23].

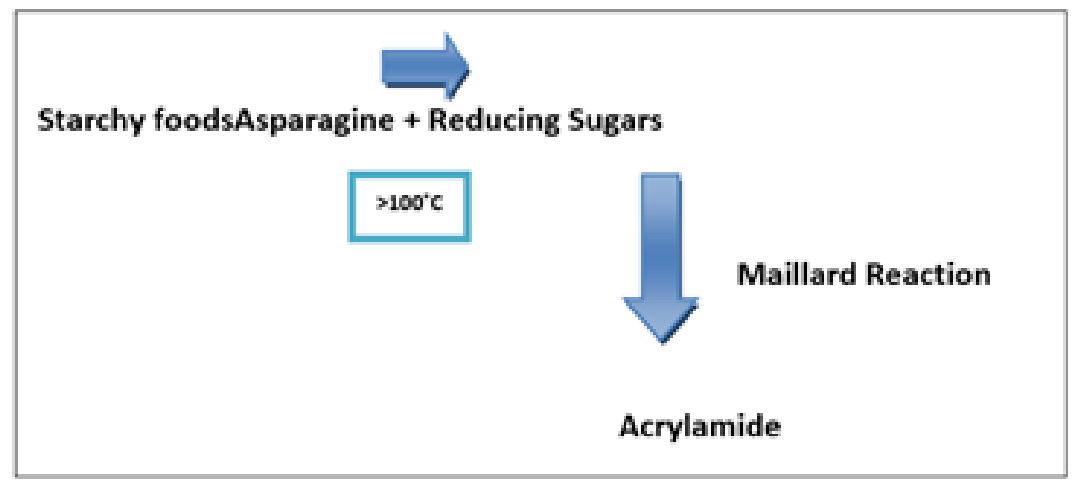

Figure 1: Reaction of Acrylamide formation.

\section{Methods of Acrylamide determination in food entities}

The increase in the levels of acrylamide day by day has led researchers to find a way to determine the presence of acrylamide and to how much extent it is present in particular foodstuff [2427]. First the detection of acrylamide was done by its derivatization which means to convert a chemical compound into a product having the same chemical structure, for example the double bond of acrylamide is broken by the addition of bromine (brominating) following by the use of as chromatography-mass spectrometry (GCMS) determination method [28-30]. With the passage of time new determination methods were discovered but without derivatization [31]. Later a new method was developed LC-MS/MS method with few amendments [32]. As for both techniques GC and HPLC (High Performance Liquid Chromatography), mass spectrometry is the main technique and due to which reason, there was a need of more durable, cheap and sensitive method for the analysis of acrylamide without making use of MS. For instance, a new technique developed in which liquid extraction and chromatography- Electron Captured Detector (GC-ECD) for the analysis of acrylamide in water (US EPA method 8032A). A technique developed that uses HPLC with ultraviolet radiations for the determination of presence of acrylamide in packed food entities. German Health Agency introduced this method in 2002. Nevertheless, broad ranges of foodstuffs analyzed by this technique can give better results because acrylamide does not have any particular wavelength of absorption $\left(\lambda_{\max }\right)$. Due to this reason, to make acrylamide detectable brominating is for GC analysis and then LC for low UV detection $(4 \mu \mathrm{g} / \mathrm{L})[33,34]$. With the increased advancement, the direct injection of the derivatization product on LC-MS has decreased the detection limit up to $0.5 \mu \mathrm{g} / \mathrm{L}$ [35]. By reviewing the papers and publishing of past few years it has been find out that there are many more methods regarding the analysis and determination of acrylamide in cooked or baked items [36-41]. In 2005, Gokmen [42] and its coworkers developed a new an analytical method for the analysis of acrylamide in potato or other baked and fried food products through reversed phase HPLCDAD method (HPLC-diode array detection). By using this method, the results were very easily obtained but it required complex pretreatment procedure for identification i.e. extraction, purification with different solutions, evaporation and clean up therefore it was concluded that its sensitivity is not higher as that of GC or MS/MS based methods. Besides all of this, recently new faster and cheaper methods are 
being introduced e.g. ELISA, electrochemical bio sensing, use of fluorescent techniques and computer vision.

\section{How acrylamide produced}

Formation: Particularly Acrylamide cannot detect in unheated or boiled foods [43]. Acrylamide in meals may be shape at some point of excessive temperature cooking via numerous mechanisms, i.e. formation via acrylic acids, formation due to dehydration/ decarboxylation of natural acids WHO [44]. A series of nonenzymatic reactions among free amino acids and reducing sugars that is accountable for the taste and color are generated at some points of baking [45]. This will provide an explanation for the formation of acrylamide in cooked food wealthy in asparagine, e.g. in cereals and potatoes [46].

In reality, the awareness of decreasing sugars in meals the number one determinant of acrylamide formation in comparison to asparagine content [47]. Then highest amount of acrylamide is present in fried, roasted, toasted, broiled and baked foods that have heated at a temperature more than $120^{\circ} \mathrm{C}$. In the next step, a chemical reaction happens called the "Maillard reaction" which involves sugar such as glucose, fructose, water, heat and asparagine content (amino acid). These mixtures cause the formation of acrylamide. Swedish studies in 2002 introduce high level of acrylamide produced during frying or baking of potato and cereal products. An essential associated reaction is the Strecker's degradation of amino acids by means of those intermediates where the amino acid decarboxylate and de-aminate to form an aldehyde. It was investigated whether this reaction provide a probable path to acrylamide. The amino acid, asparagine should be especially suitable reactant because it already has an amide group connected to a certain sequence of carbon atoms. They therefore performed a sequence of Maillard reactions between glucose and asparagine; in addition, they used different amino acids that do not have an appropriate carbon backbone for acrylamide. The large quantities of acrylamide (221mg per mole of amino acid) have discovered in equimolar mixture of asparagine and glucose that reacted at 185 ${ }^{\circ} \mathrm{C}$ in phosphate buffer in a sealed glass tube. Then temperature dependency of acrylamide formation from asparagine indicates that is favored above $100{ }^{\circ} \mathrm{C}$ and very high temperature is not important [45]. In order to investigate the role of oxidation in acrylamide formation they studied the consequences of exogenous phenolic antioxidants extracted from cranberry and oregano from Maillard reaction in fried potato slices having the capacity of antioxidant pastime [48].

Harmful effects of acrylamide: The extensive study on acrylamide highlights it as a harmful chemical in animals and humans as in having its major effects being carcinogenic, genotoxin and neurotoxin along with its minor effects in reproduction. Its most common use in industries makes it a serious chemical of concern that is causing potential damage to humans and environment along with its hundreds of benefits [49]. Children are a most common victim of acrylamide nowadays. Research on acrylamide showed that the reduction in the weight of newborn is due to the acrylamide food consumption by the pregnant women and is a key factor that points the future health of the baby. As in comparison to adult children, they consume twice the amount of acrylamide due to their small size and weight [50].

Carcinogenicity of acrylamide: According to a research survey the sudden deaths of patients with cancer were increased to 33\% in between the year 2005 ad 2015 [51]. Research studies conducted on mice and rats showed that a long-term exposure or intake to acrylamide results in various types of cancers e.g. pancreatic, prostate, breast, ovarian, and endometrial cancer [52-55]. In human and animals, acrylamide get metabolize to an epoxide metabolite called as Glycinamide (GA), by means of an enzyme referred to asCYP2E1 that leads to mutations and disrupts the DNA [56]. Analysis of acrylamide and glycinamide hemoglobin adduct levels in humans reported that there is no risk of endometrial cancer in association with acrylamide dietary intake. Likewise, no risk association of acrylamide with epithelial cancer was in observation [52]. While surprisingly experimentally proved that there is a particular association of acrylamide dietary intake with single nucleotide polymorphism and a risk of AA metabolizing enzymes cytochrome P450, family 2 with endometrial cancer and single nucleotide polymorphism with HSD3B1/B2 gene cluster is connected to the risk of ovarian cancer in humans [57]. Sufficient evidence of carcinogenicity in animals, while inadequate evidence of carcinogenicity in humans led to its classification in group 2A by the International Agency for Research on Cancer (IARC) in 1994 [58]. WHO consultation approved this in 2002.

Studies conducted on cancer showed that there is a clear connection between dietary intake and risk of developing cancer. Few studies reported possible association between dietary AA intake and cancer risk for instance the risk of lymphatic malignancy in men is directly proportional to the acrylamide consumption in food. Acrylamide in diet also increases the risk of developing cutaneous malignant tumor especially in men [59]. Most recent research on acrylamide in china reported high death rate of Chinese due to cancer that is associated with Acrylamide dietary intake [60].

Neurotoxicity of acrylamide: Experimental analysis on acrylamide showed that it has potentially harmful neurotoxic effects on human body $[61,62]$. The symptoms as numbness in upper and lower limbs along with itching are check in case of neurotoxicity [63]. In the laboratory testing, it is harmful to the rodents as it causes severe muscle weakness and dysfunction of nervous system $[64,65]$. The mechanism under which acrylamide affects is still questionable but on the other hand, several procedures are identified moderate the neurotoxicity of acrylamide. When acrylamide is interacted with kinesin motor proteins (in the direction of microtubule in neurons) causes damage to the neurons and thus resulting in the nerve cell death [66]. Observations on acrylamide also proved that it stops the up taking of neurotransmitters by pairing itself with sulfhydryl groups present on particular proteins and therefore it acts as a barrier in the release of neurotransmitters by damaging synaptic vesicles.

Reproductive toxicity of acrylamide: Until now, acrylamide is considered to be of no harm to humans in reproductive toxicity, 
however in laboratory testing on animals showed that its long-term exposure is reproductively toxic for rodents and other animals $[67,68]$. Various amounts of acrylamide and exposures in different intervals were performed in the laboratory that showed that animals exposed to acrylamide have a decreased fertility rate in males, abnormal litter sizes, decrease ability of insemination due to damaged copulatory organ, decreased sperm counts and the weight of testes were reduced [69-71]. Further studies regarding reproductive toxicity showed that in mouse long-term exposures to acrylamide and glycinamide decreases the viability of cell. Sometimes it leads to the cell death process called as apoptosis in Sertoli cell [72]. Acrylamide causes the reduction in testosterone serum and prolactin levels [73] is disrupted which may result in testicular waste, decreases in sperm count and its motility [74].

Immunotoxicity of acrylamide: The literature review on acrylamide regarding its immune toxicity is not present in detail. The experimental analysis on rats via exposure showed that it causes reduction in weight of thymus, spleen. A sharp decrease in weight of mesenteric lymph nodes was present [75]. The decreased lymphocytes count and lesions in payer's patches is in notice through oral administration at different doses [76]. However, lymphoid tissues and gut-associated tissues are more sensitive to acrylamide attack especially in rats. Observers also reported that acrylamide reduces the amount of interleukin 6, which provokes the body immune response along with the detriment of splenocyte causing proliferation [77]. In other words, it is responsible for weakening of immune system.

Hepatotoxicity of acrylamide: No reported toxicity of acrylamide regarding liver is present however, experimental analysis on animals showed that after exposure of acrylamide to adult rats for 21 days reported significant reduction in GSH of liver considered to cause decrease in level because of oxidative stress [78]. GSH is an antioxidant that is involved in the protection of cell damage caused due to the presence of reactive species e.g. peroxide and heavy metals like mercury etc. [79]. Research on acrylamide also reported the reduction in liver enzymes that help in speeding up normal chemical reaction along with protection of cell. Common enzymes of liver that are reported to be significantly reduced due to the action of AA are amino-transferase, aspartate, alanine and alkaline phosphatase [78]. Furthermore, a low level of cholesterol and triglycerides are present. An experimental analysis on drinking water was done by exposing zebra fish to water containing acrylamide in the range of 300 parts per million that causes the death of fish within 26 hours of exposure due to increased level of glucose, triglyceride and fat build up in liver causing its disruption [80].

Permissible limits of acrylamide: The extensive use of acrylamide in different forms had made it a serious concern. For instance, acrylamide is most commonly in use of industries for the treatment of water, in cosmetics, dyes fabric and textile industry. Besides this, it is a most common ingredient used in gel electrophoresis for the identification or separation of and DNA, RNA and proteins [81]. Professional exposure to acrylamide leaves serious consequences on plant workers, people handling laboratories along with industrial workers that are at the peak of risk of developing cancer in future [82]. The survey of Norway made it clear that exposure to underground water laced with acrylamide causes serious damage to workers [83]. Besides this, the serious consequences of long-term exposure of acrylamide to workers in China chemical manufacturing industry observed. The main symptoms in these workers were muscle weakness, dizziness, more sweating and paresthesia. Damaged nerves of peripheral nervous system along with blurred vision observed in some cases [82]. Surprisingly the research study in rats showed that after even third exposure to acrylamide their body is with $40 \mathrm{mg} / \mathrm{kg}$ after 4 weeks' administration and in all of them same neurological defects observed. Recent researches and surveys have made it clear that tobacco smokers are more at risk of developing cancer as compared to other population because one cigarette contains $1 \mu \mathrm{g}$ or higher levels of acrylamide. It also depends on the type of cigarette that is in use. Other tobacco containing products have about 100 to $367 \mathrm{ng} / \mathrm{g}$ of acrylamide [84]. So, the no of cigarette and its type decides how much acrylamide is being consumed by a person. The hemoglobin adducts with acrylamide along with its oxidative metabolite glycinamides both act as biomarkers that suggested the higher levels of acrylamide in smokers as compared to non-smokers [85]. The dietary exposure of acrylamide and the risk development of cancer from acrylamide have checked twice by JEFCA [86]. Chips are popular food entity among all age groups. In recent study, it was found that in non-branded chips obtained from a local shop of Lahore, Pakistan, acrylamide was present in considerable amount i.e. $2649.80 \mu \mathrm{g} / \mathrm{kg}$ [87].

Mitigation: Different strategies can be in following to mitigate the dangerous effects of acrylamide. Research on acrylamide showed that precursors of acrylamide in food are asparagine and reducing sugars. Acrylamide production can reduce by removing these precursors (CAST) Council for Agricultural Science and Technology. Potato slices when soaked in water before frying; acrylamide production will reduce up to $50 \%$ [88]. Warm water removes more asparagine's and glucose than that of simple water. Using Asparaginase can also reduce or eliminate asparagine's from potato because it splits asparagine's into aspartic acid and ammonia [89]. Use of Asparaginase reduces asparagine up to $75 \%$ in gingerbread dough and reduces it up to $50 \%$ in baked food [90]. Yeast fermentation can also reduce ACR from food items [91]. ACR production can increase due to additives and ingredients so these must be avoiding.

Fermentation of four mixtures of rye and wheat can reduce ACR production up to $77 \%$ and $87 \%$ respectively. Use of sodium hydrogen carbonate instead of sodium bicarbonate which is a baking agent and sucrose in place of honey, which is also a baking agent, can reduce ACR production by $60-70 \%$ [88]. Design of frying unit also affects ACR production, changing these units can change in asparagine production by changing thermal load Flow direction of heated oil [92]. Asparagine's if applied on chilled French fries will also reduce ACR content up to $90 \%$ and taste of French fries will 
not change [91]. Natural herbal extract when added to food items will also lessen the content of ACR formation. Bamboo leaves have antioxidants which are able to reduce production of ACR in potato crisps ranging from 30.7 to $46.9 \%$ [93]. If green tea extract added to burgers and nuggets, this would also reduce ACR production in these food items [94]. Flavonoids when added to food items these also lessen the ACR production when heated in microwave and the strength of flavonoids depends upon the number of phenolic hydroxyls [95]. Blanching and addition of Asparaginase together also minimize ACR production up to 90\% [96]. Phenolic antioxidants will also reduce the production of ACR immensely with the maximum success rate of $60 \%$ for calleoylquinic acids [97]. Dipping and saturating potatoes in water and decolorizing it minimize the ACR production in potatoes [98].

\section{Conclusion}

Long-term exposure to acrylamide causes skin irritation by damaging the smooth muscles of skin and severe damage to eye. Acrylamide has carcinogenic as well as neuro-toxic effects that can reduce by lessening the use of processed foods and fried items. Temperature must be lowered from $120^{\circ}$ for starchy foods. Furthermore, different surveys conducted to check varying effect of dietary intake of acrylamide and human cancer risk. Smokers are most likely to adapt mouth cancer so it should put into consideration. The permissible limit of acrylamide in food must not exceed $2 \%$. Different anti-cancer strategies also promoted to fight the potential effects of cancer from acrylamide. Products containing high level of acrylamide or polyacrylamide must be ban. Different phenolic antioxidants use for releasing the effect of acrylamide similarly; saturation of starchy foods and vegetables in more than $1 \mathrm{~L}$ of water can reduce the effect of acrylamide. Removal of acrylamide from food products completely still remain as a major challenge although its exposure can be minimizing by taking different measures.

\section{References}

1. Tareke E, Rydberg P, Karlsson P, Eriksson S, Törnqvist M (2002) Analysis of acrylamide, a carcinogen formed in heated foodstuffs. J Agric Food Chem 50(17): 4998-5006.

2. Mottram DS, Wedzicha BL, Dodson AT (2002) Acrylamide is formed in the Maillard reaction. Food Chem 419(6906): 448-449.

3. Stadler RH, Blank I, Varga N, Robert F, Hau J, et al. (2002) Acrylamide from Maillard reaction products. Food Chem 419(6906): 449-450.

4. Kepekci TSE, Onal C, Onal A (2012) Food Anal Methods 5: 29.

5. Sharp D (2003) Hogwash from Hogwarts. Lancet 361(9362): 982.

6. European Food Safety Authority (2012) Update on acrylamide levels in food from monitoring years 2007 to 2010. EFSA Journal 10(10): 2938.

7. Williams JSE (2005) Influence of variety and processing conditions on acrylamide levels in fried potato crisps. Food Chem 90(4): 875-881.

8. Das B, Srivastav PP (2012) Toxicol Mech Methods 22: 163.

9. Becalski A, Brady B, Feng S, Gauthier BR, Zhao T (2011) Formation of acrylamide at temperatures lower than $100^{\circ} \mathrm{C}$ : The case of prunes and a model study. Food Addit Contam 28(6): 726-730.

10. Friedman M (2003) Chemistry, biochemistry, and safety of acrylamide. A review. J Agric Food Chem 51(16): 4504-4526.
11. Hilbig A, Freidank N, Kersting M, Wilhelm M, Wittsiepe J (2004) Estimation of the dietary intake of acrylamide by German infants, children and adolescents as calculated from dietary records and available data on acrylamide levels in food groups. Int J Hyg Environ Health 207(5): 463-471.

12. Shamla L, Nisha P (2014) Acrylamide in deep-fried snacks of India. Food Addit Contam 7(3): 220-225.

13. Delgado AC (2014) Maillard reaction products: some considerations on their health effects. Clin Chem Lab Med 52(1): 53-60.

14. Gilbert PA, Khokhar S (2008) Changing dietary habits of ethnic groups in Europe and implications for health. Nutr Rev 66(4): 203-215.

15. Ouhtit Al, Sharbati M, Gupta I, Al Farsi Y (2014) Potato chips and childhood: What does the science say? An unrecognized threat? Nutr 30(10): 1110-1112.

16. Wyka J, Tajner CA, Broniecka A, Piotrowska E, Bronkowska M, et al. (2015) Estimation of dietary exposure to acrylamide of Polish teenagers from an urban environment. Food Chem Toxicol 75: 151-155.

17. Katz JM, Winter CK, Buttrey SE, Fadel JG (2012) Comparison of acrylamide intake from Western and guideline-based diets using probabilistic techniques and linear programming. Food chem Toxicol 50(3-4): 877883.

18. Mesías M, Morales FJ (2015) Acrylamide in commercial potato crisps from Spanish market: Trends from 2004 to 2014 and assessment of the dietary exposure. Food Chem Toxicol 81: 104-110.

19. Koutsidis G, De la Fuente A, Dimitriou C, Kakoulli A, Wedzicha BL, et al. (2008) Acrylamide and pyrazine formation in model systems containing asparagine. J Agric Food Chem 56(15): 6105-6112.

20. Claeys WL, De Vleeschouwer K, Hendrickx ME (2005) Kinetics of acrylamide formation and elimination during heating of an asparaginesugar model system. J Agric Food Chem 53(26): 9999-10005.

21. De Wilde T, De Meulenaer B, Mestdagh F, Govaert Y, Vandeburie S, et al. (2006) Influence of fertilization on acrylamide formation during frying of potatoes harvested in 2003 J Agric Food Chem 54(2): 404-408.

22. Chuda Y, Ono H, Yada H, Ohara TA, Matsuura EC, et al. (2003) Effects of physiological changes in potato tubers (Solanum tuberosum L.) after low temperature storage on the level of acrylamide formed in potato chips. Mori Biosci Biotech Biochem 67(5): 1188-1190.

23. Ono H, Chuda Y, Ohnishi KM, Yada H, Ishizaka M, et al. (2003) Analysis of acrylamide by LC-MS/MS and GC-MS in processed Japanese foods. Food Addit Contam 20(3): 215-220.

24. Zhu Y, Li G, Duan Y, Chen S, Zhang C, et al. (2008) Food Chem 109: 899.

25. Becalski A, Lau BPY, Lewis D, Seaman SW (2003) Acrylamide in foods: occurrence, sources, and modeling. J Agric Food Chem 51(3): 802-808.

26. Ahn JS, Castle L, Clarke DB, Lloyd AS, Philo MR (2002) Verification of the findings of acrylamide in heated foods. Food Addit Contam 19(12): $1116-1124$

27. Rosén J, Hellenäs KE, (2002) Analysis of acrylamide in cooked foods by liquid chromatography tandem mass spectrometry. Analyst 127(7): 880-882.

28. Andrawes F, Greenhouse S, Draney D (1987) Chemistry of acrylamide bromination for trace analysis by gas chromatography and gas chromatography-mass spectrometry J Chromatogr A 399: 269-275.

29. Castle L (1993) Determination of acrylamide monomer in mushrooms grown on polyacrylamide gel. J Agric Food Chem 41(8): 1261-1263.

30. Castle L, Campos MJ, Gilbert J (1991) Determination of acrylamide monomer in hydroponically grown tomato fruits by capillary gas chromatography-mass spectrometry. J Sci Food Agric 54(4): 549-555. 
31. Keramat J, LeBail A, Prost C, Soltanizadeh N, (2011) Acrylamide in foods: Chemistry and analysis: A review. Food Bioprocess Tech 4(3): 340-363.

32. Takatsuki S, Nemoto S, Sasaki K, Maitani T (2003) Determination of acrylamide in processed foods by LC/MS using column switching. J Food Hyg Soc JPN 44(2): 89-95.

33. Brown L, Rhead M, (1979) Analyst 104: 391.

34. Brown L, Rhead MM, Hill D, Bancroft KC (1982) Water Res 16: 579.

35. Cavalli S, Polesello S, Saccani G (2004) Determination of acrylamide in drinking water by large-volume direct injection and ion-exclusion chromatography-mass spectrometry. J Chromatogr A 1039(1-2): 155159.

36. Wenzl T, De La Calle MB, Anklam E (2003) Analytical methods for the determination of acrylamide in food products: a review. Food Addit Contam 20(10): 885-902.

37. Zhang Y, Zhang G, Zhang Y (2005) Occurrence and analytical methods of acrylamide in heat-treated foods. Review and recent developments. J Chromatogr A 1075(1-2): 1-21.

38. Castle L, Eriksson S (2005) Analytical methods used to measure acrylamide concentrations in foods. J AOAC Int 88(1): 274-284.

39. Kim T, Hwang ES, Lee HJ (2007) Food Chem 101: 401.

40. Pittet, Périsset A, Oberson JM (2004) Trace level determination of acrylamide in cereal-based foods by gas chromatography-mass spectrometry. J Chromatogr A 1035(1): 123-130.

41. Ren Y, Zhang Y, Jiao J, Cai Z, Zhang Y (2006) Sensitive isotope dilution liquid chromatography/electrospray ionization tandem mass spectrometry method for the determination of acrylamide in chocolate. Food Addit Contam 23(3): 228-236.

42. Gökmen V, Şenyuva HZ, Acar J, Sarığlu K (2005) Determination of acrylamide in potato chips and crisps by high-performance liquid chromatography. J Chromatogr A 1088(1-2): 193-199.

43. Tareke E, Rydberg P, Karlsson P, Eriksson S, Törnqvist M (2000) Acrylamide: a cooking carcinogen? Chem Res Toxicol 13(6): 517-522.

44. WHO (2002) Health implications of Acrylamide in food. World Health Organization?

45. Mottram DS, Wedzicha BL, Dodson AT (2002) Acrylamide is formed in the Maillard reaction. Nature 419(6906): 448-449.

46. Bråthen E, Knutsen SH (2005) Effect of temperature and time on the formation of acrylamide in starch-based and cereal model systems, flat breads and bread. Food Chem 92(4): 693-700.

47. Muttucumaru N, Powers SJ, Elmore JS, Dodson A, Briddon A, et al. (2017) Acrylamide-forming potential of potatoes grown at different locations, and the ratio of free asparagine to reducing sugars at which free asparagine becomes a limiting factor for acrylamide formation. Food Chem 220: 76-86.

48. Vattem DA, Shetty K (2003) Acrylamide in food: a model for mechanism of formation and its reduction. Innov Food Sci Emerg 4(3): 331-338.

49. Pelucchi C, Galeone C, Levi F, Negri E, Franceschi S, et al. (2006) Dietary acrylamide and human cancer. Int J Cancer 118(2): 467-471.

50. Dybing E, Farmer PB, Andersen M, Fennell TR, Lalljie SPD, et al. (2005) Human exposure and internal dose assessments of acrylamide in food. Food Chem Toxicol 43(3): 365-410.

51. Fitzmaurice C, Allen C, Barber RM, Barregard L, Bhutta ZA, et al. (2017) Global, Regional, and National Cancer Incidence, Mortality, Years of Life Lost, Years Lived With Disability, and Disability-Adjusted Life-years for 32 Cancer Groups, 1990 to 2015: A Systematic Analysis for the Global Burden of Disease Study. JAMA Oncol 3(4): 524-548.

52. Obón SM, Freisling H, Peeters PH, Lujan BL, Ferrari P, et al. (2016) Acrylamide and glycidamide hemoglobin adduct levels and endometrial cancer risk: A nested case-control study in nonsmoking postmenopausal women from the EPIC cohort. Int J Cancer 138(5): 1129-1130.

53. Obón SM, Lujan BL, Travis RC, Freisling H, Ferrari P, et al. (2016) Epidem Biomar 25: 127

54. Pelucchi C, Galeone C, Negri E, Bosetti C, Serraino D, et al. (2016) Nutr Cancer 68: 187-192.

55. Pelucchi C, Rosato V, Bracci PM, Li D, Neale RE (2016) Dietary acrylamide and the risk of pancreatic cancer in the International Pancreatic Cancer Case-Control Consortium (PanC4). Ann Oncol 28(2): 408-414.

56. Ghanayem BI, Witt KL, El Hadri L, Hoffler U, Kissling GE, et al. (2005) Comparison of germ cell mutagenicity in male CYP2E1-null and wildtype mice treated with acrylamide: evidence supporting a glycidamidemediated effect. Biol Reprod 72(1): 157-163.

57. Hogervorst JG, van den Brandt PA, Godschalk RW, van Schooten FJ, Schouten LJ (2017) Interactions between dietary acrylamide intake and genes for ovarian cancer risk. Eur J Epidemol 32(5): 431-441.

58. IARC Acrylamide (1994) In IARC monographs on the evaluation of carcinogenic risks to humans. Some industrial chemicals, WHO, Geneva, Switzerland, 60: 389.

59. Lipunova N, Schouten LJ, van den Brandt PA, Hogervorst JG (2017) A prospective cohort study on dietary acrylamide intake and the risk for cutaneous malignant melanoma. Eur J Cancer Prev 26(6): 528-531.

60. Liu ZM, Tse LA, Ho SC, Wu S, Chen B, et al. (2017) Dietary acrylamide exposure was associated with increased cancer mortality in Chinese elderly men and women: a 11-year prospective study of Mr. and Ms. OS Hong Kong. J Cancer Res Clin 143(11): 2317-2326.

61. Spencer PS, Schaumburg HH (1974) A review of acrylamide neurotoxicity. Part I. Properties uses and human exposure. Can J Neurol Sci 1(2): 143-150.

62. LoPachin RM (2004) The changing view of acrylamide neurotoxicity. Neurotoxicol 25(4): 617-630.

63. Hagmar L, Törnqvist M, Nordander C, Rosén I, Bruze M, et al. (2001) Health effects of occupational exposure to acrylamide using hemoglobin adducts as biomarkers of internal dose. Scand J Work Env Hea 27(4): 219-226.

64. McCollister DD, Oyen F, Rowe VK (1964) Toxicology of acrylamide. Toxicol Appl Pharm 103: 172-181.

65. Miller MS, Spencer PS (1985) The mechanisms of acrylamide axonopathy. Annu Rev Pharmacol 25: 643-666.

66. Sickles DW, Tsai J (1996) Fund Appl Toxicol 30: 302.

67. Dearfield KL, Abernathy CO, Ottley MS, Brantner JH, Hayes PF (1988) Mutat Res Rev Gen Tox 195: 45.

68. Tyl RW, Friedman MA (2003) Effects of acrylamide on rodent reproductive performance. Reprod Toxicol, 17(1): 1-13.

69. Hashimoto K, Tanii H (1985) Mutagenicity of acrylamide and its analogues in Salmonella typhimurium. Mutation Res/Genetic Toxicol 158(3): 129-133.

70. Sakamoto J, Hashimoto (1986) Mutat Res Rev Gen Tox 59: 201.

71. Zenick H, Hope E, Smith MK (1986) Reproductive toxicity associated with acrylamide treatment in male and female rats. J Toxicol Env Heal A 17(4): 457-472.

72. Yilmaz BO, Yildizbayrak N, Aydin Y, Erkan M (2017) Evidence of acrylamide- and glycidamide-induced oxidative stress and apoptosis in Leydig and Sertoli cells. Human Exp Toxicol 36(12): 1225-1235.

73. Ali SF, Hong JS, Wilson WE, Uphouse LL, Bondy SC (1983) Effect of acrylamide on neurotransmitter metabolism and neuropeptide levels in several brain regions and upon circulating hormones. Arch Toxicol 52(1): 35-43. 
74. Burek JD, Albee RR, Beyer JE, Bell TJ, Carreon RM, et al. (1980) Subchronic toxicity of acrylamide administered to rats in the drinking water followed by up to 144 days of recovery. J Environ Pathol Tox 4(56): 157-182.

75. Zaidi SIA, Raisuddin S, Singh KP, Jafri A, Husain R, et al. (1994) Immunopharm Immunot, 16: 247.

76. Yener Y, Sur E, Telatar T, Oznurlu Y (2013) The effect of acrylamide on alpha-naphthyl acetate esterase enzyme in blood circulating lymphocytes and gut associated lymphoid tissues in rats. Exp Toxicol Pathol 65(1-2): 143-146.

77. Fang Jin, Liang CL, Jia XD, Ning LI (2014) Biomed Environ Sci 27: 401.

78. Gedik S, Erdemli ME, Gul M, Yigitcan B, Bag HG (2017) Hepatoprotective effects of crocin on biochemical and histopathological alterations following acrylamide-induced liver injury in Wistar rats. Biomed Pharmacother 95: 764-770.

79. Pompella A, Visvikis A, Paolicchi A, De Tata V, Casini AF (2003) The changing faces of glutathione, a cellular protagonist. Biochem Pharmacol 66(8): 1499-1503.

80. Kim SM, Baek JM, Lim SM, Kim JY, Kim J (2015) Modified Lipoproteins by Acrylamide Showed More Atherogenic Properties and Exposure of Acrylamide Induces Acute Hyperlipidemia and Fatty Liver Changes in Zebrafish. Cardiovasc Toxicol 15(4): 300-308.

81. Friedman M (2003) Chemistry, biochemistry, and safety of acrylamide. A review. J Agric Food Chem 51(16): 4504-4526.

82. Pennisi M, Malaguarnera G, Puglisi V, Vinciguerra L, Vacante M et al. (2013) Neurotoxicity of Acrylamide in Exposed Workers. Int J Env Res Pub He 10(9): 3843-3854.

83. Kjuus, Goffeng LO, Heier MS, Sjöholm H, Øvrebø S, et al. (2004) J Work Env Hea 49: 21

84. Moldoveanu SC, Gerardi AR (2011) J Chromatogr Sci 49: 234.

85. Schettgen T, Kütting B, Hornig M, Beckmann MW, Weiss T, et al. (2004) Int Arch Occ Env Hea 77: 213.

86. FAO (2006) WHO joint expert committee on food additives \& world health organization. Evaluation of certain food contaminants: sixtyfourth report of the Joint FA.
87.Zahra N, Kalim I, Khurshid Z, Ahmad I, Saeed MK (2018) Pak J Anal Environ Chem 19: 91.

88. Amrein TM, Schönbächler B, Escher F, Amadò R (2004) Acrylamide in gingerbread: critical factors for formation and possible ways for reduction. J Agric Food Chem 52(13): 4282-4288.

89. Pedreschi F, Kaack K, Granby K (2008) The effect of asparaginase on acrylamide formation in French fries. Food Chem 109(2): 386-392.

90. Konings EJ, Ashby P, Hamlet CG, Thompson GA (2007) Acrylamide in cereal and cereal products: a review on progress in level reduction. Food Addit Contam 24(1): 47-59.

91. Haase NU (2008) Potential food safety concerns in fried potato products in Kenya. Potato Res 51: 239-258.

92. Medeiros VR, Mestdagh F, De Muer N, Van Peteghem C, De Meulenaer B (2010) Effective quality control of incoming potatoes as an acrylamide mitigation strategy for the French fries industry. Food Addit Contam A 27(4): 417-425.

93. Yu F, Qian X, Zeng Z, Zhao X, Hou R, et al. (2017) Antioxidant effect of bamboo leaves on the reproduction and embryonic development-related gene expression in mouse embryonic stem cells. J Clin Exp Med 10(8): $11454-11463$

94. Soncu ED, Kolsarici N (2017) Microwave thawing and green tea extract efficiency for the formation of acrylamide throughout the production process of chicken burgers and chicken nuggets. J Sci Food Agric 97(6): 17901797.

95. Cheng, Chen X, Zhao S, Zhang Y (2015) Food Chem 168: 90.

96. Pedreschi F, Mariotti S, Granby K, Risum J (2011) Acrylamide reduction in potato chips by using commercial asparaginase in combination with conventional blanching. LWT Food Sci Technol 44(6): 1473-1476.

97. Constantinou C, Koutsidis G (2016) Investigations on the effect of antioxidant type and concentration and model system matrix on acrylamide formation in model Maillard reaction systems. Food Chem 197: 769-775.

98. Jackson L S, Al Taher F (2005) Effects of consumer food preparation on acrylamide formation. In Chemistry and safety of acrylamide in food. Springer, Boston, MA pp: 447-465. 